\title{
Laparoscopic sterilization falope ring technique update: A 10-year study of 2,831 cases
}

MARTIN J. ROITMAN, D.O., FACOOG

Bridgeton, Missouri

This report covers the author's experience with 2,831 cases of laparoscopic sterilization in which a silicone rubber band applicator was employed. The study was performed at an outpatient surgery facility in Saint Louis, Missouri. All of the surgical procedures were performed by the author, and this appears to be one of the largest individual studies in the literature at the present time. The method of surgery as well as the patient population are described, and the results, including significant complications, are analyzed. The pregnancy rate was 1.4 per thousand cases. A significant number $(22.7$ percent) of the patients had undergone at least one prior pelvic or abdominal operation. A large number of patients had concomitant surgery performed at the time of sterilization. No major pelvic injuries occurred in the series. Most common complications were transection of an oviduct ( 39 cases), uterine perforation ( 29 cases), difficulty in achieving pneumoperitoneum (18 cases), and bleeding mesosalpinx (13 cases). The average surgical time was 14.8 minutes; anesthesia time was 31.5 minutes, and recovery room time was 78.6 minutes. Based on this long-term study, the falope ring operative technique is a safe and effective procedure for ambulatory surgical sterilization and appears to have significant advantages over other operative techniques.

In 1974 , Yoon and associates ${ }^{1}$ reported on a new laparoscopic sterilization approach-the silicone rubber band technique. My study of this procedure began in 1975, and a preliminary report ${ }^{2}$ on 131 cases was published in 1977. The present report of 10 years' experience with 2,831 patients confirms the simplicity, safety, and effectiveness of the technique. All of the procedures were performed on an outpatient basis in a free-standing outpatient surgery center. ${ }^{3}$ The study is one of the largest individual studies in the American literature.

\section{Materials and methods}

\section{Laparoscopic silicone applicator}

Instruments used in this series of 2,831 cases primarily were single- or double-puncture laparoscopes manufactured by Kli (now Cabot) Laboratories. The single puncture was used in 2,524 cases, the double puncture in 179 cases. A single-puncture instrument made by Storz was used in 15 cases. Forty-five cases were combined with rings and coagulation, 53 cases by bipolar coagulation, and 3 cases by unipolar coagulation. Minilaparotomy was performed in 2 cases; in 10 cases, diagnostic laparoscopy was performed because sterilization could not be accomplished.

The two-cylinder laparoscopic silicone ring applicator employs a standard laparoscopy lens system and fiberoptic light source. A grasping forceps for lifting a segment of the fallopian tube is within the inner cylinder. The outer surface of the inner cylinder is fitted with a silastic ring. (The newer equipment allows two rings to be placed at one time, so that the ligation can be accomplished without reloading the applicator.) The ring is displaced onto the inner cylinder by means of a loading cone. The ring is made of a combination of silicone and rubber that allows specific elastic power and 90 to 100 percent memory. It is $2.2-\mathrm{mm}$. thick, with an inner diameter of $1 \mathrm{~mm}$. and an outer diameter of 
$3.6 \mathrm{~mm}$.; when placed on the surface of the inner cylinder, it is stretched to $6 \mathrm{~mm}$.

The inner cylinder of the device slides to and fro, and the grasping forceps are exposed as the handle is moved forward. In moving the handle backward after grasping a segment of fallopian tube, the tube is drawn into the inner cylinder. Simultaneously, the silicone ring is forced onto the fallopian tube.

\section{Study group and procedures}

A total of 2,831 patients were included in the study. Of these, 1,716 patients were referred by the Family Planning Council of Saint Louis, Missouri, through its various family planning agencies, and 1,115 patients were from my private practice, which involved welfare recipients as well as middle-class women. The patients all desired permanent sterilization. All procedures were performed at a freestanding surgical center named Surgicare, Inc., (now Community Surgical Center, Inc.).

The study was begun in March 1975 and includes all cases performed through 1984. Age, marital status, and parity were not primary criteria in the study. All women who requested permanent sterilization and were older than legal age were considered for the procedure. Exception was made in 15 cases $(0.5$ percent); these patients exhibited severe mental retardation and were carefully evaluated and had consultations recommending the procedure.

In 1975 , I used both ring and cautery techniques in my practice, but by 1976 , it was my intent to use the silastic ring for all patients.

\section{Presurgical and laparoscopic procedures}

Age distribution of the patients is noted in Table 1. The youngest patient was 13 years and the oldest 49 years; average age was 30.2 years. Marital status distribution is presented in Table 2 . The average weight was 143.8 pounds, with a range of 80 to 340 pounds; 224 patients ( 7.9 percent) weighed in excess of 200 pounds. Based on 2,741 patients, the average number of living children was 2.6 (90 patients not recorded).

Previous major abdominal or pelvic surgery had been performed for 642 patients (22.7 percent). Table 3 lists the number and Table 4 the type of major operations. Most of these patients had undergone cesarean section, appendectomy, cholecystectomy, or pelvic laparotomy. Four patients had five previous major operations. Table 5 shows the distribution of cesarean sections, with 209 patients having undergone at least one prior $\mathrm{C}$-section.

Preoperative evaluation and physical examination were performed for each patient, and the necessary consent forms were reviewed fully in

\begin{tabular}{|lcc|}
\hline \multicolumn{3}{|l|}{ TABLE 1. AGE DISTRIBUTION OF 2,831 FALOPE RING STERILIZA- } \\
TION PATIENTS. \\
\hline $\begin{array}{l}\text { Age group } \\
\text { (years) }\end{array}$ & $\begin{array}{c}\text { No. of } \\
\text { patients }\end{array}$ & $\begin{array}{c}\text { Percent of } \\
\text { patients }\end{array}$ \\
\hline$<21$ & 15 & 0.5 \\
$21-25$ & 559 & 19.8 \\
$26-30$ & 832 & 29.4 \\
$31-35$ & 728 & 25.7 \\
$36-40$ & 471 & 16.6 \\
$41-45$ & 187 & 6.6 \\
$>45$ & 39 & 1.4 \\
\hline
\end{tabular}

\begin{tabular}{|lcc|}
\hline \multicolumn{3}{|l|}{ TABLE 2. MARITAL STATUS DISTRIBUTION OF 2,831 FALOPE RING } \\
STERILIZATION PATIENTS. \\
\hline Marital & $\begin{array}{c}\text { No. of } \\
\text { patients }\end{array}$ & $\begin{array}{c}\text { Percent of } \\
\text { patients }\end{array}$ \\
status & 468 & 16.5 \\
\hline Single & 1,265 & 44.7 \\
Married & 362 & 12.8 \\
Separated & 683 & 24.1 \\
Divorced & 53 & 1.9 \\
Widowed & & \\
\hline
\end{tabular}

\begin{tabular}{|c|c|c|}
\hline $\begin{array}{l}\text { No. of procedures } \\
\text { per patient }\end{array}$ & $\begin{array}{c}\text { No. of } \\
\text { patients }\end{array}$ & $\begin{array}{l}\text { Total no. of } \\
\text { procedures }\end{array}$ \\
\hline 1 & 483 & 483 \\
\hline 2 & 113 & 226 \\
\hline 3 & 38 & 114 \\
\hline 4 & 4 & 16 \\
\hline 5 & 4 & 20 \\
\hline Total & $\overline{642}$ & $\overline{859}$ \\
\hline
\end{tabular}

accordance with the standards set by the Department of Health, Education, and Welfare (DHEW). Counseling often was done in group sessions; it was found that this method stimulated more questions than when the patients were counseled individually. Each patient also was given an opportunity to have her questions answered privately during her physician examination. The procedure usually was scheduled in accordance with DHEW's waiting period, and the patient was instructed to fast after 12:00 a.m. on the day of surgery.

Hemoglobin and hematocrit levels were determined and urinalysis and a pregnancy test were performed on the day of surgery. An evaluation was made by an anesthesiologist prior to the adminstration of general anesthesia. No preoperative medications were employed. Chest roentgenography was performed at the discretion of the anesthesiologist.

The patient was taken to the operating suite and placed in a modified lithotomy position. The abdomen, perineum, and vagina were prepared with a povidone-iodine preparation, and appropriate drapes were applied. A bimanual pelvic examina- 
TABLE 4. DISTRIBUTION OF PREVIOUS MAJOR ABDOMINAL OR PELVIC SURGERY BY TYPE.

\begin{tabular}{|lc|}
\hline $\begin{array}{l}\text { Type of } \\
\text { procedure }\end{array}$ & $\begin{array}{c}\text { No. of } \\
\text { procedures }\end{array}$ \\
\hline Cesarean section & 322 \\
Appendectomy & 176 \\
Cholecystectomy & 152 \\
Pelvic laparotomy & 128 \\
Umbilical herniorrhaphy & 29 \\
Gastric resection or bypass & 13 \\
Inguinal herniorrhaphy & 11 \\
Splenectomy & 8 \\
Stab or gunshot wound of abdomen & 3 \\
Bowel resection & 2 \\
Bladder suspension & 2 \\
Hiatal herniorrhaphy & 2 \\
Volvulus & 1 \\
Colostomy & 1 \\
Abdominal fistula & 1 \\
Liver resection & 1 \\
Tubal ligation & 1 \\
Diaphragmatic abscess & 1 \\
Miscellaneous & 5 \\
(thyroidectomy and open-heart surgery) & \\
\hline Total & 859 \\
\hline
\end{tabular}

TABLE 5. PREVIOUS CESAREAN SECTIONS IN SERIES OF 2,831 PATIENTS.

\begin{tabular}{|c|c|c|}
\hline $\begin{array}{l}\text { No. of } \\
\text { procedures } \\
\text { per patient }\end{array}$ & $\begin{array}{c}\text { No. of } \\
\text { patients }\end{array}$ & $\begin{array}{c}\text { Total } \\
\text { no. of } \\
\text { procedures }\end{array}$ \\
\hline 1 & 122 & 122 \\
\hline 2 & 66 & 132 \\
\hline 3 & 17 & 51 \\
\hline 4 & 3 & 12 \\
\hline 5 & 1 & 5 \\
\hline Total & 209 & 322 \\
\hline
\end{tabular}

tion was performed. A weighted speculum was introduced, and the cervix was grasped with a tenaculum and brought downward and forward. For purposes of manipulation during the procedure, a blunt uterine sound was placed in the uterus. A Verres needle was introduced into the infraumbilical fold, and, utilizing 2 liters or less of carbon dioxide, a pneumoperitoneum was created. The needle was removed, a small incision was made in the infraumbilical fold, and a trocar and cannula were introduced. The trocar was then removed, with the trocar sleeve left in place.

Next, the laparoscope and silicone rubber band applicator were inserted through the trocar sleeve, and the pelvic cavity with its contents were visualized. A spinal needle was inserted suprapubically, and approximately $2 \mathrm{ml}$. of 1 percent Xylocaine solution was infused on the surface of each oviduct. After the oviducts were fully identified from the cornu to the fimbria, the grasping forceps were used to pick up the fallopian tube approximately 1 to 2 inches from the cornu, at a point of greatest mobility. The oviduct was drawn into the inner cylinder of the ring applicator device.

\begin{tabular}{|lc|}
\hline TABLE 6. CONCOMITANT SURGERY PERFORMED AT TIME OF \\
STERILIZATION. & \\
\hline & No. of \\
Procedure & 599 \\
\hline Dilatation and curettage & 236 \\
Cryocautery of cervix & 103 \\
Lysis of adhesion & 80 \\
Removal of intrauterine contraceptive & \\
device & 54 \\
Electrocautery of cervix & 11 \\
Salpingochromoscopy & 10 \\
Myomectomy & 5 \\
Aspiration of ovarian cyst & 4 \\
Cervical polypectomy & 4 \\
Cervical biopsy & 4 \\
Removal of nevi & 4 \\
Coagulation of uterine perforation site & 3 \\
Biopsy of vagina & 3 \\
Cautery of condylomata & 2 \\
Umbilical herniorrhaphy & 2 \\
Aspiration of peritoneal fluid & 2 \\
Excision of labial cyst & 2 \\
Cervical cold knife coagulation & 2 \\
Marsupialization of Bartholin's gland cyst & 1 \\
Posterior colporrhaphy & 1 \\
Breast biopsy & 1 \\
Coagulation of endometrial implants & 1 \\
Excision of Gartner's duct cyst & 1 \\
Excision of hymenal tags & 1 \\
Partial vulvectomy & 1 \\
Excision of abdominal lesions & 1 \\
Excision of vaginal septum & 1 \\
Excision of Bartholin's cyst & 1 \\
Coagulation of mesosalpinx bleeder & 1 \\
Removal of perforated intrauterine & 1 \\
contraceptive device & 1 \\
Excision of vulva lesion & 1 \\
Vacuum suction curettage & 1 \\
& \\
\hline
\end{tabular}

One silicone rubber band was applied to the grasping segment of the fallopian tube by moving the outer cylinder forward. After application of the silicone ring, the grasping forceps were moved forward out of the inner cylinder to release the segment of the fallopian tube that had been occluded by the band. Similarly, the opposite tube was grasped and a silicone ring was applied. Injection of indigo carmine dye to test patency was not performed. Following removal of the laparoscope, the pneumoperitoneum was relieved. In most instances, the puncture site was sutured with no. 4.0 chromic catgut using either a standard or subcuticular technique, or atraumatic allis forceps were used to accomplish skin closure.

A surgical center nurse phoned each patient at home on the day after surgery and recorded her responses on her medical chart.

\section{Concomitant procedures}

Table 6 illustrates the concomitant surgical procedures performed at the time of sterilization. Dilatation and curettage, cryocautery of cervix, lysis of adhesions, removal of intrauterine contraceptive 
devices, and electrocautery of the cervix accounted for these majority of procedures.

\section{Anesthesia}

General anesthesia was used in all but 8 cases. The choice of anesthetic agent was left to the anesthesiologist. Not all patients had endotracheal intubation. In almost all cases, 1 percent Xylocaine was infused on the surface of the oviducts, because early study had shown that it helped to reduce postoperative nausea and vomiting. It may also have helped to reduce postoperative pain, which seems to be significant when silastic rings are employed. The most significant recovery room prob-

\begin{tabular}{|lc|}
\hline \multicolumn{2}{|l|}{ TABLE 7. OPERATIVE COMPLICATIONS ENCOUNTERED DURING } \\
SURGERY.
\end{tabular}

lem was vomiting, which occurred in 429 cases. Postoperatively, patients were given oral medications containing codeine or a similar substance for pain control.

\section{Procedural times}

The average operating room time for all cases, including those involving concomitant procedures, was 14.8 minutes. The average anesthesia duration was 30.5 minutes, and the recovery room time was 78.6 minutes.

\section{Results}

\section{Complications}

No major injuries to the pelvis occurred in this series. Table 7 illustrates the type of complications encountered at the time of surgery.

The most common complication was transection of the oviduct, which occurred as the oviduct was drawn into the cylinder by the grasping forceps because the tube was too thick to be introduced into the laparoscope. With experience, this complication can sometimes be overcome by "milking" the tube (grasping it and slowly drawing it into the operative channel and releasing it). This maneuver is performed several times until the tube can be drawn into the laparoscope and the ring applied. In each case of transection, a "click" sound was heard. When this occurred, an attempt was made to ligate

\begin{tabular}{|lll|}
\hline \multicolumn{2}{|l|}{ TABLE 8. CASES REQUIRING HOSPITAL ADMISSION. } \\
\hline No. & \multicolumn{1}{|c|}{ Reason for hospitalization } \\
\hline 1 & Previously undiagnosed ectopic pregnancy & Comments \\
2 & Cornual pregnancy, which ruptured 3 days & Transfer \\
& after ligation & Negative pregnancy test \\
3 & Umbilical hematoma & Patient dismissed within 24 hours \\
4 & Undiagnosed hematoperitoneum, probable & Patient hospitalized 48 hours \\
(tubal abortion & (transfer) \\
5 & Urinary tract infection & Matient dismissed within 24 hours \\
6 & Severe scoliosis & Patient hospitalized 72 hours (transfer) \\
\hline
\end{tabular}

\begin{tabular}{|c|c|c|c|c|}
\hline No. & $\begin{array}{l}\text { Date of } \\
\text { surgery }\end{array}$ & $\begin{array}{c}\text { Year of } \\
\text { pregnancy }\end{array}$ & Outcome & $\begin{array}{l}\text { Re-evaluation } \\
\text { comments }\end{array}$ \\
\hline 1 & $11 / 8 / 76$ & 1978 & Spontaneous abortion & $\begin{array}{l}\text { Two rings originally placed } \\
\text { on right tube. No dye } \\
\text { spilled at repeat } \\
\text { laparoscopy, but right } \\
\text { tube was coagulated. }\end{array}$ \\
\hline 2 & $11 / 7 / 77$ & 1979 & $\begin{array}{l}\text { Voluntary termination of } \\
\text { pregnancy }\end{array}$ & $\begin{array}{l}\text { Dye passed on right side, } \\
\text { and right tube was coagu- } \\
\text { lated. }\end{array}$ \\
\hline 3 & $10 / 14 / 80$ & 1981 & $\begin{array}{l}\text { Voluntary termination of } \\
\text { pregnancy }\end{array}$ & $\begin{array}{l}\text { No dye was passed, but } \\
\text { bilateral coagulation was } \\
\text { performed. }\end{array}$ \\
\hline 4 & $8 / 2 / 83$ & 1984 & Carried to term & $\begin{array}{l}\text { Postpartum ligation was } \\
\text { performed. }\end{array}$ \\
\hline
\end{tabular}


the oviduct on each side of the transection with a silicone band, or the procedure was converted to a cautery technique.

\section{Hospital admissions}

As noted in Table 8, there were 6 hospital admissions for any cause in the entire series. In 1 case, a cornual pregnancy that ruptured 3 days later was not recognized at the time of surgery.

\section{Pregnancies}

The 4 known pregnancies that occurred are described in Table 9 . The pregnancy rate was 1.4 per thousand.

\section{Comment}

As is evident in the present series, the silicone rubber band applicator for laparoscopic sterilization is a safe and effective way to achieve outpatient sterilization. Also, tubal reconstruction may be possible in those rare instances when such reanastomosis may be desirable. ${ }^{4}$ Because thermoenergy is not required, there are no bowel burns, and the procedure should be considered by physicians who already are utilizing laparoscopic ster- ilization techniques that utilize thermocautery.

Appreciation is expressed to Mrs. Linda Vetter for her statistical analysis.

1. Yoon, I.B., Wheeless, C.R., Jr., and King, T.M.: A preliminary report on a new laparoscopic sterilization approach. The silicone rubber band technique. Am J Obstet Gynecol 120:132-6, Sep 74

2. Roitman, M.J.: Laparoscopic sterilization. Falope ring technique JAOA 76:735-8, Jun 77

3. Greenspan, J.R., et al.: Tubal sterilization performed in freestanding ambulatory care surgical facilities in the United States in 1980. J Reprod Med 29:237-41, Apr 84

4. Siegler, A.M., Hulka, J., and Peretz, A.: Reversibility of female sterilization. Fertil Steril 43:499-510, Apr 85

Chi, I.C., and Wilkins, L.: Internal tubal sterilization in obese women. An assessment of risks. Am J Obstet Gynecol 152:292-7, 1 Jun 85

Dr. Roitman is chairman of the Department of Obstetrics and Gynecology, Normandy Osteopathic Hospitals, St. Louis, Missouri. He is also medical director, Community Surgical Center, St. Louis.

Dr. Roitman, WomensCare, Inc., 3394 McKelvey Road, Bridgeton, Missouri 63044. 
DESCRIPTION: EOch milliliter of NASALCROM* (cromolyn sodium nasol solution, USP) contains $40 \mathrm{mg}$ cromolyn sodium in purified water with berzalkonium chloride $0.01 \%$ and EDTA (edelote disodium) $0.01 \%$ INDICATIONS: NASALCROM is ind NOICATIONS: NasALCROM is ind. of the for then of the symploms of allergic ininitis. CONIRANDICATIONS: NASALCROM is contraindicated in those patients who hove shown typersensitivity to any of the ingredients.

PRECAUTIONS: General: SOMne potients may experience transient nosol stinging and/or sneezing immedictel/ stinging and or snoezing inmediotel

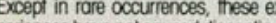
periences have not

In view of the biliary and renal routes of excretion for cromolyn sodium, consideration should be given to decreasing the dosoge or discontinuing the odministration of the drug in patients with impaired renal ar hepotic tunction Carcinogenesis, Mutagenesis, and Carcinogenesis, Mulagenesis, and impoirinent of fortily. Long lerm studies in mice (12 months intraperitoned trediment fillowed by 6 months observation), hamsters (12 months intraperitoned treaiment followed by 12 months observation), and rats (18 months subcutaneous treatment) showed no neoplastic effect of cromolyn sodium.

No evidence of chromosomal damag or cytotoxicity was obtained in various mutogenesis studies.

No evidence of impaired fertility was shown in laboratory animal reproducfion studies.

Pregnancy: Pregnancy Category B Reproduction studies with cromolyn sodium administered parenterally to pregnant mice, rats, and rabbits in doses up to 338 times the human clincal doses producod no evidence of fotal matformations. Adverse fotol et cols (increased resorptions and tects (increased resorplions and de creased felth weigni) were noled only at the very high parenteral doses the produced malernal hoxicily. There are, however, no adequate and wellcontrolled studies in pregnant women. Becouse animal reproduction studies are not always predictive of human response, this drug should be used during pregnancy only if clearly needed. Drug Interaction During Pregnancy: Cromolyn sodium and isoproterenol were studied following subcutaneous injections in pregnant mice. Cromolyn sodium alone in doses of 60 to 540 $\mathrm{mg} / \mathrm{kg}$ ( 38 to 338 fimes the human $\mathrm{mg} / \mathrm{kg}$ (38 to 338 fimes the human dose) did not cause significant increases in resorptions or major ma"formations. isoproterenol alone of a dose of $2.7 \mathrm{mg} / \mathrm{kg}$ (90 times the human malformations. The oddition of cromoIyn sodium (338 times the human dose) to isoproterenol (90 fimes the human dose) appears to have increased the incidence of both resorptions and malformations.

Nursing Mothers: It is not known Nursing Mothers: It is not known Whether this drug is excreted in human creted in human milk coution should be exercised when NASALCROM is administered to a nursing woman Pediatric Use: Solfety and effectiveness in children below the oge of 6 years have not been established.

ADVERSE REACTIONS: The most frequent adverse reoctions occurring in quent adverse reactions occurring in the 430 patients included in the clintsneezing ( 1 in 10 patients), nasal stinging ( 1 in 20 ), nosal burning (1 in 25), and nasol irritation ( 1 in 40). Heodoches and bod taste were reported in about 1 in 50 patients. Epistoxis, postrusal drip and mash were staxis, posinasal drip, and rash were reported in less the patients. One patient in the clinical

Adverse reoctions which have $\propto c$ curred in the use of other cromolyn sodium formulations for inhalation include angioedema, joint pain and swelling urticaria, cough, and wheezing. Other reoctions reported rarely are serum sickness, peniarteritic vasculiins, polymyositis, pericarditis, photodermatitis, extoliative dermatitis, peripheral neuritis, and nephrosis. NASALCROM" is a registered NASALCROM $*$ is a registered
trodemark of Fisons plc.

FISONS

FISONS CORPORATION

1. Dato on file, Fisons Corporation. From perennial allergic

\section{"I LIKE HOW FAST IT WORKS TO STOP MY ALLERGIES, WITHOUT MAKING ME DROWSY."}

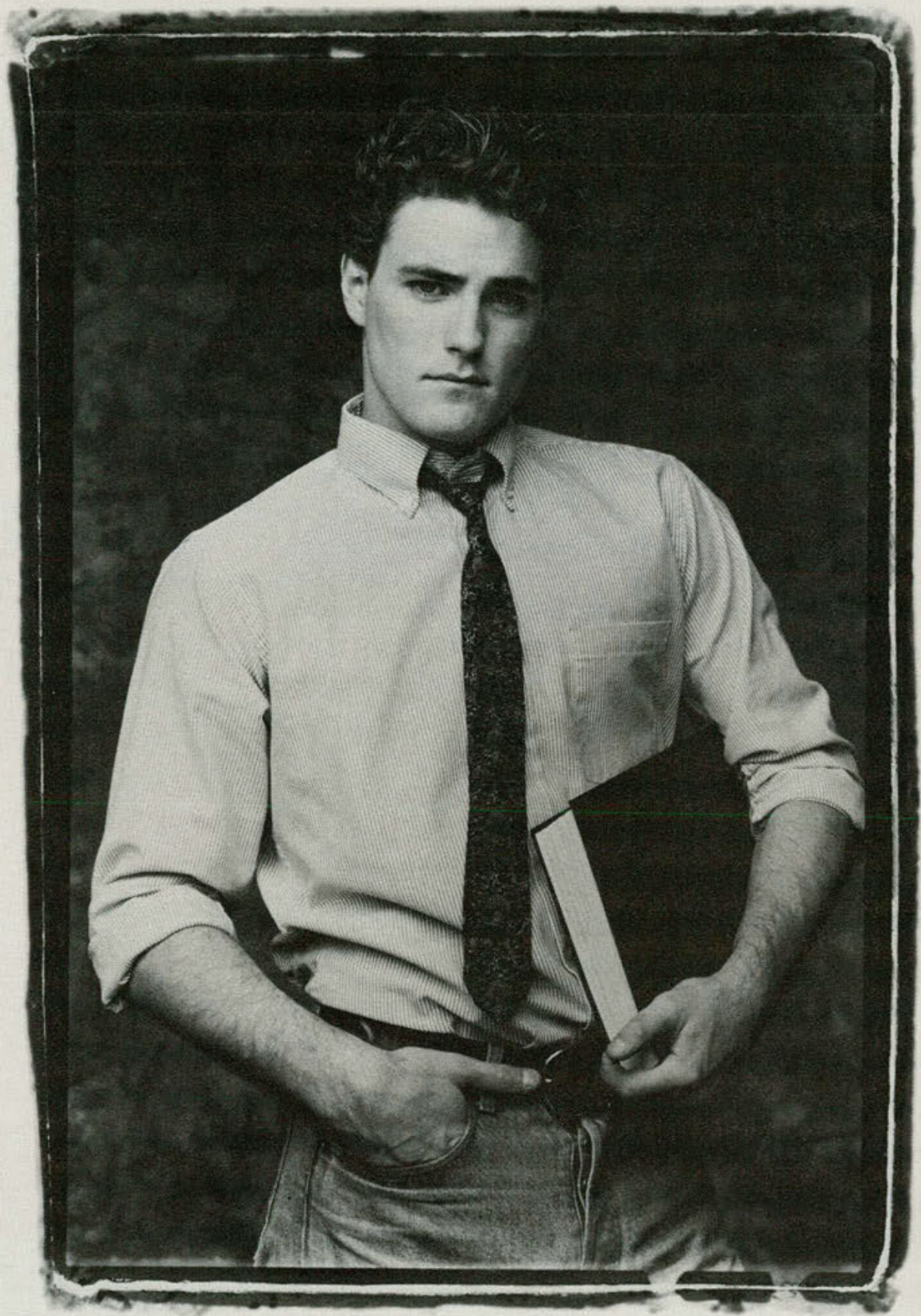

NASALCROM works rapidly-usually within the first few doses-to relieve the congestion, rhinorrhea, and sneezing of seasonal allergic rhinitis. However, for many patients, the side effects of traditional medications can be as troublesome as the allergic symptoms themselves. Unlike these medications, NASALCROM is extremely well-tolerated therapy, virtually uncomplicated by serious side effects, tolerance or contraindications. 